\title{
What's in a voice? Dolphins do not use voice cues for individual recognition
}

\author{
Laela S. Sayigh ${ }^{1,2} \cdot$ Randall S. Wells $^{3}$ Vincent M. Janik ${ }^{4}$
}

Received: 14 October 2016/Revised: 14 July 2017/Accepted: 28 July 2017/Published online: 8 August 2017

(C) The Author(s) 2017. This article is an open access publication

\begin{abstract}
Most mammals can accomplish acoustic recognition of other individuals by means of "voice cues," whereby characteristics of the vocal tract render vocalizations of an individual uniquely identifiable. However, sound production in dolphins takes place in gas-filled nasal sacs that are affected by pressure changes, potentially resulting in a lack of reliable voice cues. It is well known that bottlenose dolphins learn to produce individually distinctive signature whistles for individual recognition, but it is not known whether they may also use voice cues. To investigate this question, we played back non-signature whistles to wild dolphins during brief capture-release events in Sarasota Bay, Florida. We hypothesized that nonsignature whistles, which have varied contours that can be shared among individuals, would be recognizable to dolphins only if they contained voice cues. Following established methodology used in two previous sets of playback experiments, we found that dolphins did not respond differentially to non-signature whistles of close relatives versus known unrelated individuals. In contrast, our previous studies showed that in an identical context, dolphins reacted strongly to hearing the signature whistle or even a synthetic version of the signature whistle of a close
\end{abstract}

Laela S. Sayigh

1sayigh@hampshire.edu

1 School of Cognitive Science, Hampshire College, Amherst, MA 01002, USA

2 Biology Department, Woods Hole Oceanographic Institution, Woods Hole, MA, USA

3 Chicago Zoological Society's Sarasota Dolphin Research Program, c/o Mote Marine Laboratory, Sarasota, FL, USA

4 Scottish Oceans Institute, School of Biology, University of St. Andrews, St. Andrews, UK relative. Thus, we conclude that dolphins likely do not use voice cues to identify individuals. The low reliability of voice cues and the need for individual recognition were likely strong selective forces in the evolution of vocal learning in dolphins.

Keywords Dolphin · Playback experiment · Non-signature whistle $\cdot$ Voice cues $\cdot$ Individual recognition

\section{Introduction}

Most mammals, including humans, can accomplish recognition of other individuals by means of "byproduct distinctiveness" (Boughman and Moss 2003), whereby the shape and size of the vocal tract render vocalizations produced by a given individual uniquely identifiable (e.g., bats: Balcombe 1990; primates: Belin 2006; Rendall et al. 1996; Snowdon and Cleveland 1980; sheep: Searby and Jouventin 2003; fur seals: Charrier et al. 2002). Such identifying features have been referred to as "voice cues." Sound production in odontocete cetaceans (toothed whales, dolphins, and porpoises) does not involve the larynx as in other non-human mammals, but instead involves the vibration of membranes in the "monkey/phonic lips-dorsal bursae" complex of the nasal region (Au et al. 2012; Cranford et al. 1996; Madsen et al. 2010, 2012; Ridgway and Carder 1988). These gas-filled nasal sacs are susceptible to pressure changes associated with changes in depth (Ridgway et al. 2001), which have been suggested to result in a lack of reliable voice cues in these animals (Tyack 2000). A lack of voice cues could have been a driving force in the evolution of individually distinctive signature whistles that are found in many delphinid species (e.g., common bottlenose dolphins, Tursiops truncatus, Caldwell 
et al. 1990; Indo-Pacific bottlenose dolphins, Tursiops aduncus, Gridley et al. 2014; common dolphins, Delphinus delphis, Caldwell and Caldwell 1968; Pacific white-sided dolphins, Lagenorhynchus obliquidens, Caldwell and Caldwell 1971; spotted dolphins, Stenella plagiodon, Caldwell et al. 1973; Pacific humpback dolphins, Sousa chinensis, van Parijs and Corkeron 2001; Guiana dolphins, Sotalia guianensis, de Figueiredo and Simão 2009; Lima and Le Pendu 2014). Such "designed individual signatures" (Boughman and Moss 2003) have not been documented in any non-human mammals other than delphinid cetaceans to date, and may share some of the functions of human names (Janik and Sayigh 2013).

Signature whistles were first described by Melba and David Caldwell in the 1960s (Caldwell and Caldwell 1965). In studies of bottlenose dolphins under human care, they found that each dolphin predominantly produced one unique whistle contour (pattern of frequency changes over time) when isolated from conspecifics. Although signature whistles are defined as the predominant whistle that occurs in isolation (Caldwell et al. 1990), they are also important vocalizations when dolphins are free-swimming. Cook et al. (2004) found that approximately 50\% of whistles produced by undisturbed groups of dolphins in Sarasota Bay, Florida, were either signature or probable signature whistles. The Caldwells' pioneering work has been upheld by numerous other researchers over the past 5 decades (e.g., Agafonov and Panova 2012; Bruck 2013; Burdin et al. 1975; Cook et al. 2004; Esch et al. 2009a, b; Fripp et al. 2005; Harley 2008; Janik et al. 1994, 2006, 2013; Janik and Slater 1998; King et al. 2013, 2014; Luís et al. 2015; Miksis et al. 2002; Nakahara and Miyazaki 2011; Papale et al. 2015; Quick and Janik 2012; Sayigh et al. 1990, 1995, 1999, 2007; Sidorova et al. 1990; Sidorova and Markov 1992; Tyack 1986; Watwood et al. 2004, 2005). Probably signature whistles will continue to be identified in additional species as techniques are utilized for identification of vocalizing individuals, such as hydrophone arrays (e.g., Quick et al. 2008) and acoustic tags (e.g., Johnson and Tyack 2003). Such identifications will also be facilitated by a recently described technique to identify signature whistles from single hydrophone recordings of multiple individuals, which uses the temporal patterning of signature whistles to differentiate them from non-signature whistles (Janik et al. 2013).

Non-signature whistles (which have also been called "variant" whistles) have been defined as any whistle other than the signature (Caldwell et al. 1990). Unlike signature whistles, non-signature whistles tend to be highly variable in contour, with many different contour types, some of which are shared among individuals (Janik and Slater 1998). To date, very little research has focused on nonsignature whistles, and next to nothing is known about how they function in the natural communication system of dolphins. Sayigh et al. (1990) found that males in the longterm resident Sarasota Bay, Florida, bottlenose dolphin community (Wells 2014) tended to produce more nonsignature whistles than did females, although this was based on a small sample of 12 dolphins. They speculated that females may be selected to produce more stereotyped vocalizations than males, as one of the primary roles of signature whistles appears to be maintenance of contact between a mother and her calf. Example spectrograms of non-signature whistles from six different dolphins are shown in Fig. 1. For comparison purposes, examples of signature whistles from the same six individuals are also shown.

Dolphins can recognize one another by means of their signature whistles (Sayigh et al. 1999) and can also recognize individuals by hearing the frequency contour of the signature whistle alone, with all potential voice cues removed (Janik et al. 2006). However, the possibility that dolphins may use voice cues as an additional means of recognizing individuals remains open. We hypothesized that non-signature whistles, given their lack of stereotypy and the fact that general types can be shared across individuals, would be recognizable to other dolphins only if they contained characteristic voice cues identifying the vocalizer. We tested this hypothesis by playing back nonsignature whistles to wild dolphins during brief capturerelease events in Sarasota Bay, Florida, using the identical protocol as in Sayigh et al. (1999) and Janik et al. (2006). These earlier studies found that target dolphins turned more toward the playback speaker in response to whistles from related versus unrelated (but familiar) individuals. Thus, we predicted that dolphins would turn more toward the speaker in response to non-signature whistles of related versus unrelated (but familiar) individuals if they were able to recognize non-signature whistles by means of voice cues.

\section{Methods}

Our study was carried out with the resident community of bottlenose dolphins (Tursiops truncatus) near Sarasota Bay, Florida, USA. This dolphin community has been the focus of a long-term research program since 1970 (Wells et al. 1987; Scott et al. 1990). The community of about 160 resident dolphins spans up to five concurrent generations and includes individuals up to 67 years of age (Wells 2003, 2014; R. S. Wells, unpublished data). Since 1984, acoustic recordings of these dolphins have been made during occasional brief capture-release events, at which animals are assessed for various health and basic biological parameters (Wells and Scott 1990; Wells et al. 2004). 

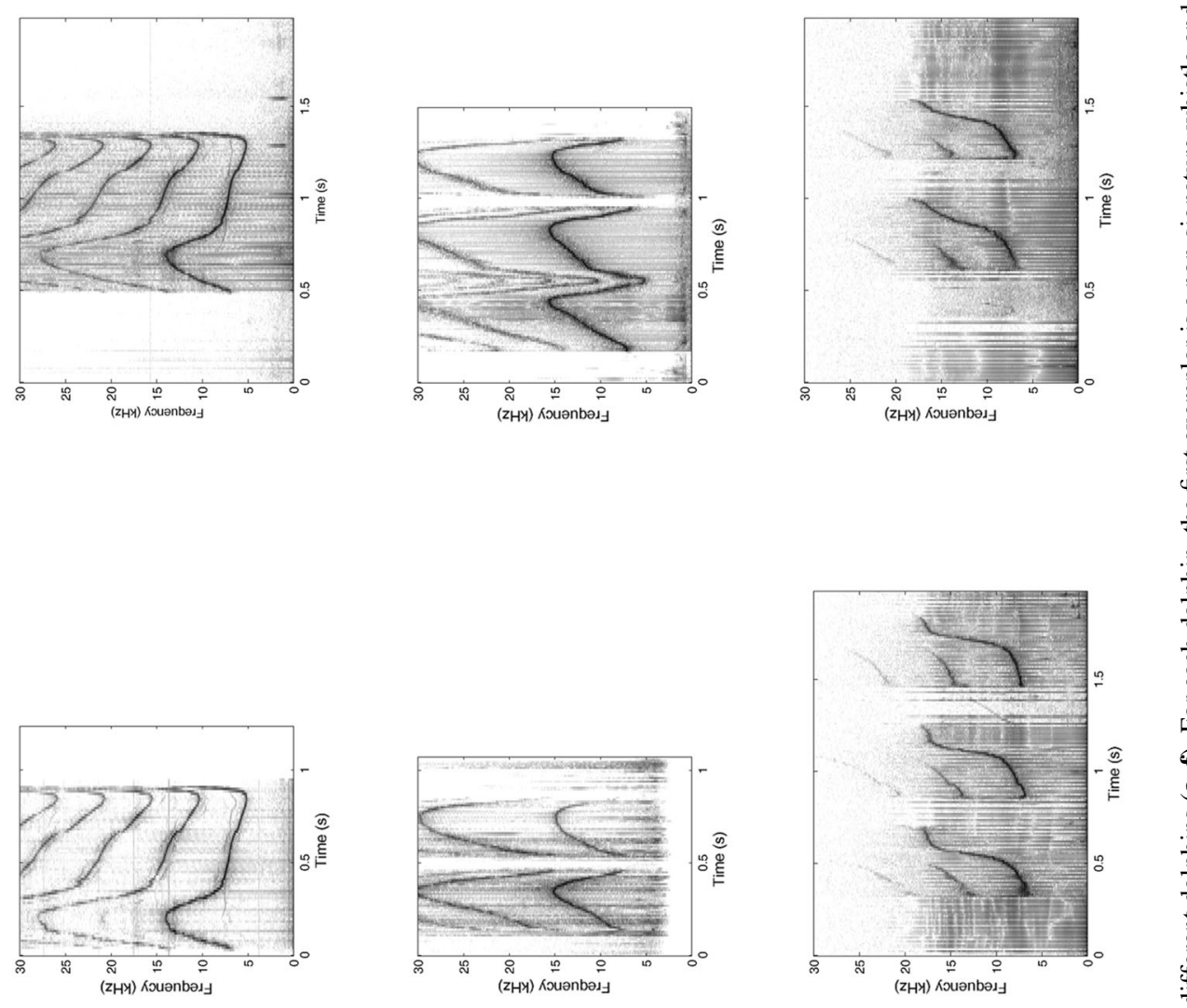

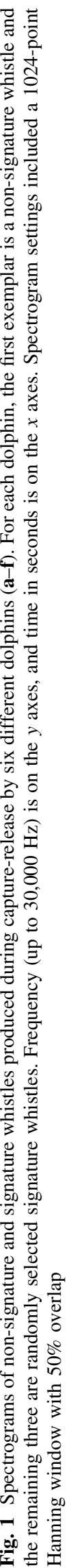
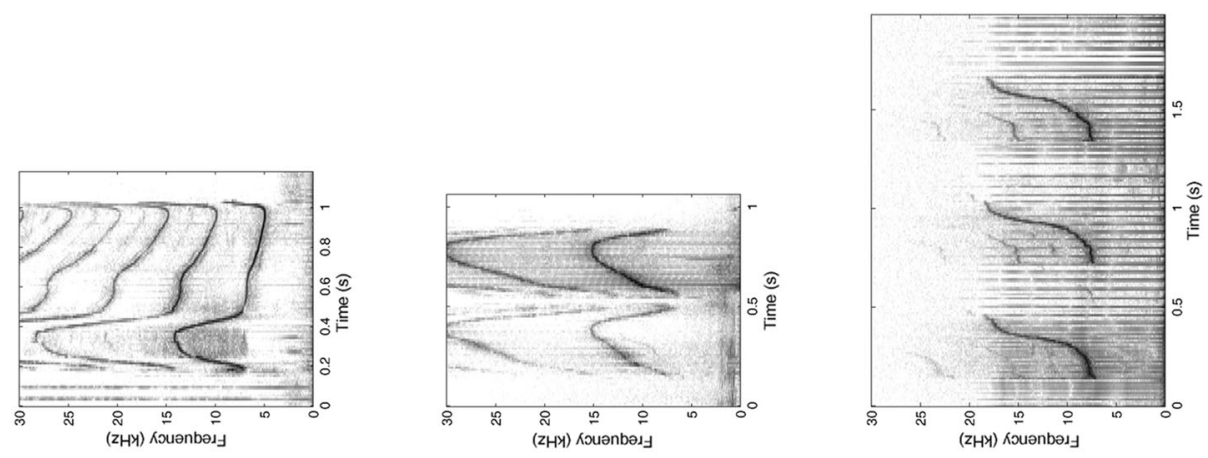

요

品

j.

륭

.0 .0

完

苋

莺
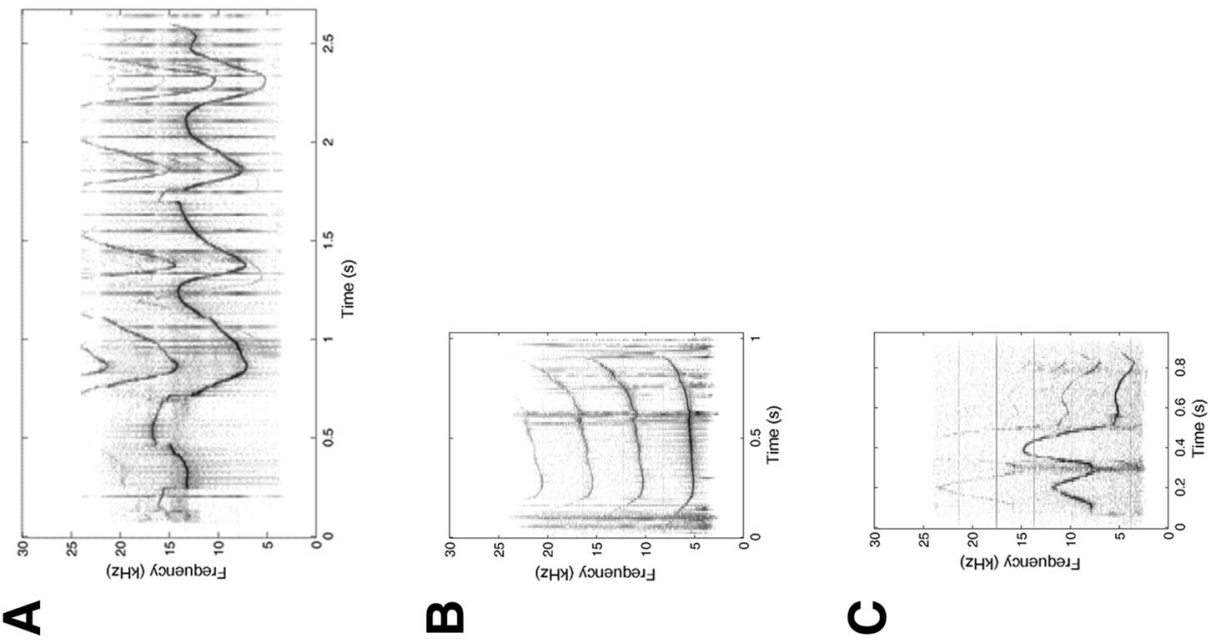

m

0 

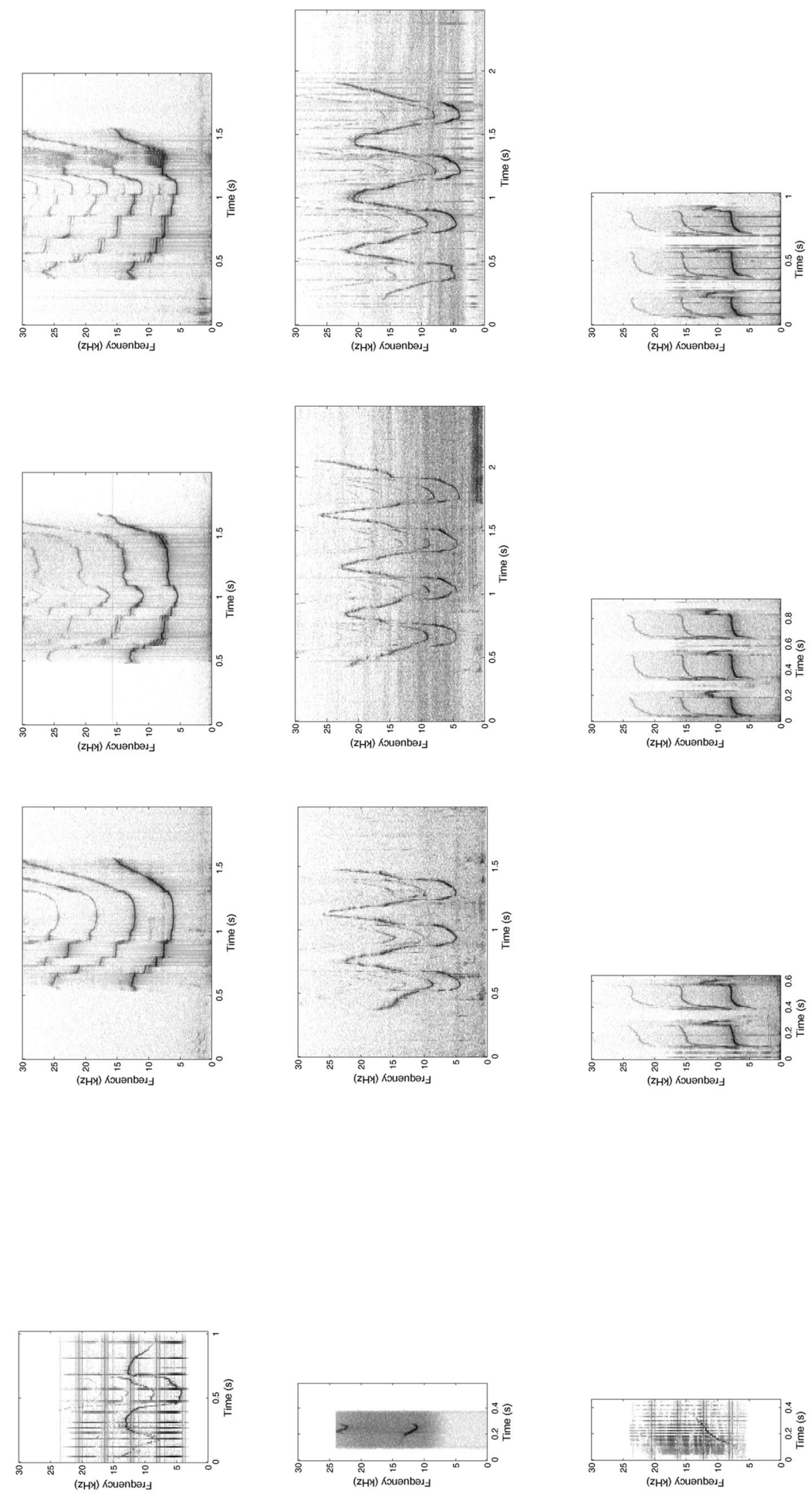

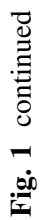


During capture-release, a $500 \times 4 \mathrm{~m}$ net is deployed from a small outboard vessel in water that is generally less than $2 \mathrm{~m}$ in depth. This creates a net corral that contains a small group (generally 1-4) of dolphins for short (1-4 h) periods of time. Throughout this time, while animals are either being held in the net corral or being examined out of the water, animals are recorded with suction cup hydrophones placed on the melon (forehead). This results in recordings that are generally high in signal-to-noise ratio. Whistles were recorded with hydrophones that were either custom built at the Woods Hole Oceanographic Institution or built by High Tech, Inc. (Gulfport, MI). Recordings were made onto a variety of different media over the years. From 1984 to 1989 , Marantz or Sony stereo-cassette recorders were used (frequency response approximately $20-20,000 \mathrm{~Hz}$ ), followed by Panasonic AG-6400 or AG-7400 videocassette recorders (frequency response approximately 20-32,000 Hz) through 2005. Since 2006, recordings have been made digitally, on a Sound Devices 744T recorder (sampled at $96 \mathrm{kHz}$ ). We now have a library of recordings of 272 dolphins, most of which have been recorded on multiple occasions (up to 18).

This recording library was used to select stimuli for the playback experiments. Typically dolphins produce large numbers of signature whistles during capture-release (e.g., Esch et al. 2009b), but non-signature whistles are occasionally produced as well. We selected a single non-signature whistle from each of 126 individual dolphins and used these to create 30 -s playback sequences, with each containing 8-12 repetitions of the same non-signature whistle, depending on whistle length. The sequences thus contained approximately the same overall whistle content, as fewer exemplars were played of longer whistles. Overall stimulus durations (calculated by multiplying the number of stimuli presented by the length of each stimulus) were compared for related (mean $=6.3 \mathrm{~s}$ ) versus unrelated stimuli (mean $=6.8 \mathrm{~s}$ ) with a Wilcoxon signed-ranks test and were not found to be significantly different $(N=40$, $\mathrm{W}=362 ; Z=-0.38, P=0.70)$.

A key aspect of this study is that we used the identical playback paradigm as in Sayigh et al. (1999) and Janik et al. (2006), so that results could be compared among the three sets of experiments. A target animal was presented with whistle stimuli from two familiar individuals, one related (as determined through long-term observations and confirmed through genetic testing) and one unrelated. Related individuals were usually mothers or independent offspring, but were occasionally siblings. The two stimulus animals had both associated with the target animal at similar levels over the previous two years, as calculated by coefficients of association (Cairns and Schwager 1987) derived from boat-based photographic identification survey data; these values were derived by dividing the number of sightings of two animals together by the total number of sightings of both individuals. When possible, the two stimulus animals were also matched for age and sex. Coefficients of association were compared for related (mean $=0.15)$ versus unrelated $($ mean $=0.05)$ pairings with a Wilcoxon signed-ranks test and were not found to be significantly different $(N=40, W=220 ; Z=-1.56$, $P=0.12$ ).

As in the previous studies, the response variable measured was head turns toward the playback speaker. Playbacks were conducted during eight capture-release sessions from February 2004 through May 2014.

All of the following field and analysis methods are identical to those of Sayigh et al. (1999) and Janik et al. (2006), but will be described briefly here. We used a LL9162 underwater speaker (Lubell Labs, Columbus, OH) connected to a car power amplifier to play back sounds to the dolphins. Sound files were played from a Dell laptop computer. The frequency response for the combined system was $240-20,000 \mathrm{~Hz} \pm 3 \mathrm{~dB}$. The source level was preset to produce a received level at a 2-m distance from the speaker (the location of our experimental animal) that approximated the received level of whistles produced by a nearby dolphin (as judged by the experimenters). Individual stimuli in each playback were normalized for average amplitude. Playbacks were monitored with a hydrophone next to the speaker, and vocalizations of the target dolphin were recorded with a suction cup hydrophone attached to the melon for the duration of the experiment. If there were other animals present during a playback, either in the water or on the deck of the boat, their whistles were also recorded with suction cup hydrophones. Recordings were made with either a Panasonic AG-7400 video recorder (2004-2005) or a Sound Devices 744T digital recorder (2006-2014), with frequency responses described above. Playback sessions were recorded on either a Sony DCRTRN 320 or a Canon Vixia HFR40 digital video camera from a platform on a boat approximately $2 \mathrm{~m}$ above the water surface at the speaker position (Fig. 2). The speaker was suspended from an anchored boat at approximately $1 \mathrm{~m}$ depth, and approximately $2 \mathrm{~m}$ to one side of the target animal.

Dolphins were held loosely by about $4-5$ handlers during the experiments but were able to turn their head freely in response to playbacks. All people holding the animal were blind to the playback sequence and could not hear in air when the stimuli were being played. Each target animal was held in position for a minimum of 5-10 min prior to an experiment so as to acclimate it to its surroundings. Each playback sequence lasted $30 \mathrm{~s}$ and was followed by $5 \mathrm{~min}$ of silence in order to document any continued responses by the target dolphin. We balanced the order of stimulus presentation, such that whistles from the related individual were played first in 20 trials and from the unrelated 


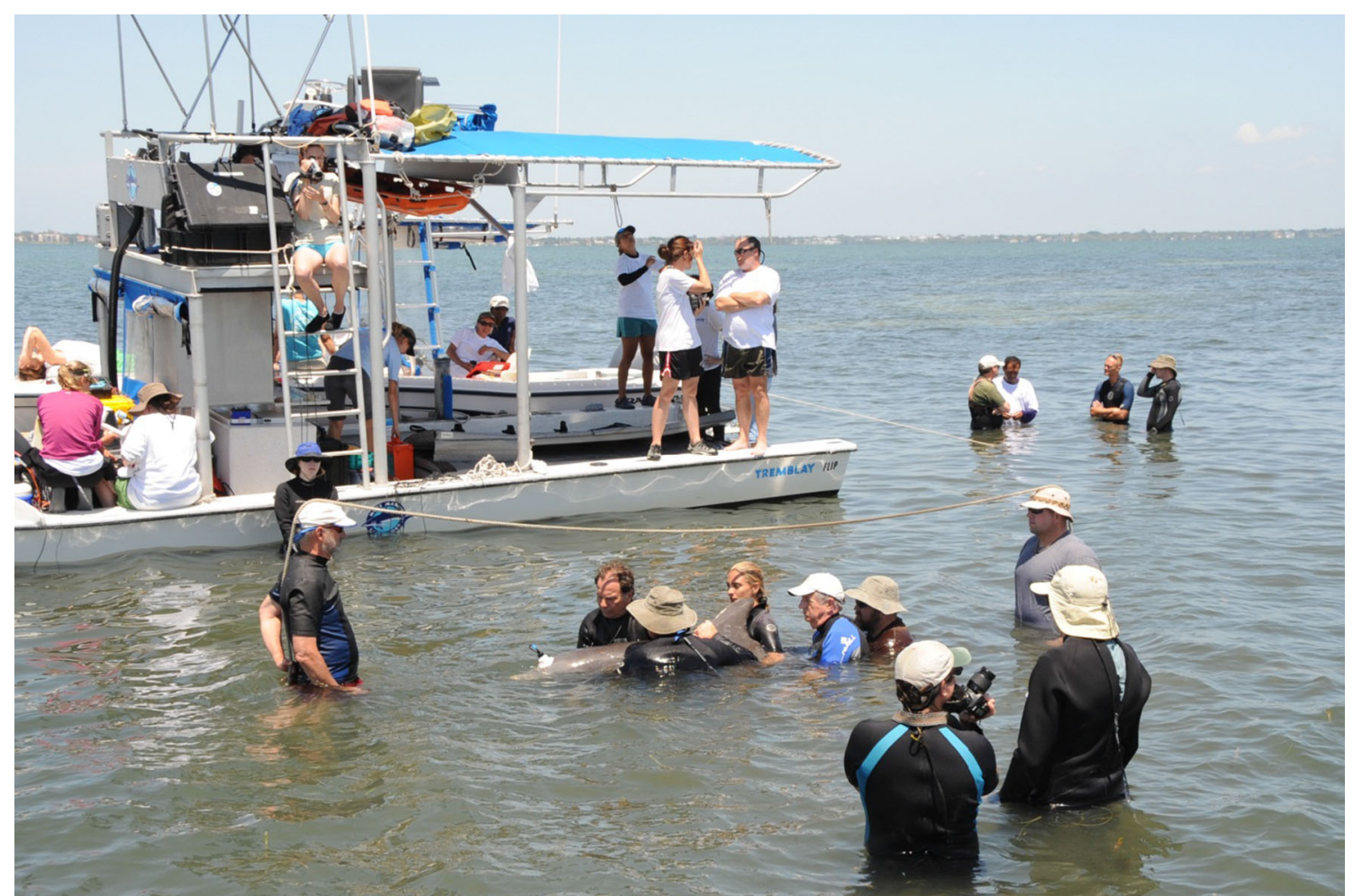

Fig. 2 Playback experimental setup, showing the position of the videographer (sitting on top of the ladder on the boat), the playback speaker (held by the person at the foot of the ladder wearing a blue hat), and the target dolphin with a suction cup hydrophone on its

individual in 20 trials. We counted head turns greater than $20^{\circ}$ toward the playback speaker within a 5.5 -min period from the start of a playback as a response. Anything less than $20^{\circ}$ was not counted because animals frequently moved back and forth within this range. Head turns were scored from video recordings of the playback sessions, without knowledge of the order of playback stimuli being presented. We compared the number of head turns toward non-signature whistles of related versus unrelated individuals. Each experiment was scored by at least two individuals, and scores were found to have a high level of agreement, with the overall statistical trends identical for both sets of scores ( $W$ scores from the Wilcoxon signedranks test comparing head turns to related versus unrelated stimuli were 290 and 292). Thus, again to be consistent with our earlier experiments, we used only one set of scores (those of author LS) for analyses. Whistle responses to playbacks were examined in Adobe Audition.

In addition to comparing responses to whistles of related and unrelated individuals, we examined effects of presentation order of the stimuli and sex of the target animal. As in our previous published studies (Sayigh et al. 1999; Janik et al. 2006), all data were tested with Wilcoxon signed-ranks tests. By keeping all aspects of this study identical to the previous studies, we were able to directly compare their results. melon. Photograph courtesy of Jim Schulz, Chicago Zoological Society, taken under National Marine Fisheries Service Scientific Research Permit No. 522-1785

We also calculated effect size by dividing the $\mathrm{Z}$ score of the Wilcoxon signed-ranks test by the square root of the number of trials (Pallant 2007) and compared effect size in our published signature whistle playbacks to that observed in the current study. We compared the differences in number of head turns to related versus unrelated playbacks in our published studies to those observed in the current study with a Mann-Whitney $U$ Test. We combined results from our natural (Sayigh et al. 1999) and synthetic (Janik et al. 2006) whistle experiments to obtain comparable sample sizes for these comparisons.

\section{Results}

Dolphins did not respond differentially, in terms of head turns toward the speaker, to non-signature whistles of close relatives versus known unrelated individuals $(N=40$, $W=292 ; Z=-0.64, \quad P=0.52 ;$ Table 1$)$. The mean number of head turns toward non-signature whistles of related individuals was 10.8 versus 12.1 toward non-signature whistles of known unrelated individuals. These results contrast with our previously published signature whistle playback experiments (Sayigh et al. 1999; Janik et al. 2006), which showed significant differential 
Table 1 Number of head turns (HT) toward the playback speaker following related and unrelated non-signature whistle stimuli, and coefficients of association $(\mathrm{CoA})$ between target and stimulus animals; male target animals are in bold

\begin{tabular}{|c|c|c|c|c|}
\hline Target animal ID & HT related stimulus & HT unrelated stimulus & CoA related stimulus & CoA unrelated stimulus \\
\hline FB07 & 22 & 15 & 0 & 0.024 \\
\hline FB11 & 13 & 14 & 0.03 & 0.062 \\
\hline FB54 & 20 & 25 & 0.026 & 0.025 \\
\hline FB90 & 23 & 29 & 0.116 & 0.106 \\
\hline $\mathrm{FB} 133^{\mathrm{a}}$ & 13 & 10 & 0.149 & 0.142 \\
\hline FB135 ${ }^{\mathrm{a}}$ & 7 & 16 & 0.833 & 0.056 \\
\hline $\mathrm{FB} 137^{\mathrm{a}}$ & 18 & 14 & 0.885 & 0.106 \\
\hline $\mathrm{FB} 137^{\mathrm{a}}$ & 8 & 0 & 0 & 0.019 \\
\hline FB151 & 2 & 1 & 0.286 & 0.1 \\
\hline FB155 & 16 & 27 & 0.006 & 0.006 \\
\hline $\mathrm{FB} 155^{\mathrm{a}}$ & 19 & 15 & 0.039 & 0.07 \\
\hline $\mathrm{FB} 159^{\mathrm{a}}$ & 10 & 3 & 0.054 & 0.059 \\
\hline FB179 & 16 & 12 & 0.455 & 0.078 \\
\hline FB181 & 3 & 1 & 0.079 & 0.039 \\
\hline $\mathrm{FB} 187^{\mathrm{a}}$ & 13 & 13 & 0.174 & 0.153 \\
\hline FB199 & 5 & 6 & 0 & 0 \\
\hline FB203 & 4 & 6 & 0.078 & 0.073 \\
\hline $\mathrm{FB} 205^{\mathrm{a}}$ & 4 & 15 & 0.116 & 0.019 \\
\hline FB209 & 4 & 2 & 0.279 & 0.083 \\
\hline $\mathrm{FB} 221^{\mathrm{a}}$ & 1 & 0 & 0.327 & 0.078 \\
\hline FB229 & 1 & 5 & 0.4 & 0.034 \\
\hline FB241 & 3 & 0 & 0.19 & 0.132 \\
\hline FB10 & 16 & 16 & 0 & 0 \\
\hline FB20 & 1 & 0 & 0 & 0 \\
\hline FB92 $^{\mathrm{a}}$ & 5 & 8 & 0.033 & 0.025 \\
\hline $\mathrm{FB100}^{\mathrm{a}}$ & 3 & 3 & 0 & 0 \\
\hline FB128 & 3 & 1 & 0 & 0.031 \\
\hline FB138 & 19 & 27 & 0.072 & 0.113 \\
\hline FB138 $^{\mathrm{a}}$ & 5 & 6 & 0 & 0.018 \\
\hline FB146 & 28 & 35 & 0.008 & 0.024 \\
\hline FB148 & 5 & 8 & 0.041 & 0.069 \\
\hline FB178 & 18 & 18 & 0.045 & 0.073 \\
\hline FB182 & 7 & 10 & 0.032 & 0.011 \\
\hline FB188 & 45 & 46 & 0.056 & 0.059 \\
\hline FB196 & 20 & 51 & 0.019 & 0.01 \\
\hline FB220 & 8 & 5 & 0.024 & 0.075 \\
\hline FB250 & 6 & 9 & 0 & 0.027 \\
\hline FB252 $^{\mathrm{a}}$ & 5 & 4 & 0.094 & 0.037 \\
\hline FB276 & 9 & 6 & 0 & 0.014 \\
\hline $\mathrm{FB280}^{\mathrm{a}}$ & 3 & 1 & 0.986 & 0.136 \\
\hline
\end{tabular}

${ }^{a}$ Experiments that were possibly compromised in some way (see text)

responses to signature whistles of related versus known unrelated individuals (combined results: $N=34$, $W=105 ; Z=-2.79, P=0.005$; mean values of 17.3 and 14.2 toward related and unrelated, respectively). Effect size in our combined signature whistle experiments was 0.33 (sample size of 34 paired trials), representative of a medium effect (Cohen 1988), whereas effect size in the non-signature whistle playbacks reported here (sample size of 40 paired trials) was only 0.07 , representative of a negligible effect. In addition, the effect was in the opposite direction to that observed in our signature whistle playbacks; in the present study, animals turned more (although 
not significantly) to non-signature whistles of unrelated animals, whereas in our previous studies animals turned significantly more toward signature whistles of related individuals. The differences between the number of head turns to related versus unrelated playbacks in our previously published experiments (average difference $=3.1$ ) and in the unrelated playbacks described in the current study (average difference $=-1.3$ ) were significantly different $\quad\left(N_{1}=34, \quad N_{2}=40, \quad U=417.5 ; \quad Z=-2.84\right.$, $P=0.004)$.

Presentation order had a marginally significant effect on head-turning behavior, with means of 12.5 head turns toward the first stimulus and 10.3 head turns toward the second stimulus $(N=40, \quad W=193.5 ; \quad Z=-2.19$, $P=0.028)$. However, this result was not significant after applying a Bonferroni correction to account for multiple testing of the same data. Sex of the target animal did not affect head-turning behavior. Females were found to show almost identical head-turning responses to non-signature whistles of related versus unrelated individuals (means of 9.9 and 10.6, respectively, $N=22, \quad W=111.5$; $Z=-0.139, P=0.89$ ). Males showed a slightly higher but still nonsignificant tendency to turn more toward nonsignature whistles of unrelated animals (mean $=14.1$ ) than to related animals (mean $=11.4 ; N=18, \quad W=35$; $Z=-1.42, P=0.16)$.

There were 14 experiments that may have been compromised by various factors (Table 1); thus data were also analyzed with these experiments excluded. Factors that may have compromised experiments included exposure to stimuli prior to the experiment (three cases), a playback stimulus that was from an animal in the same capturerelease session (one case), a playback stimulus that contained crossover from another whistle (one case), and disruption of the playback setup during an experiment (one case). We also considered 7 experiments that were conducted after auditory evoked potential (AEP) experiments to be potentially compromised, given that these experiments involved playing back stimuli of varying frequencies through jawphones. A final factor is that three individuals (FB137, FB138, and FB155) each received two playbacks in two different years. By chance, two of the duplicate playbacks (FB137 and FB138) were among the possibly compromised playbacks mentioned above, so only one additional experiment was removed to account for these.

Results from the remaining 26 experiments were similar to those from the larger data set of 40 experiments. Dolphins did not respond differentially to non-signature whistles of close relatives (mean head turns 12.2) versus known unrelated individuals (mean head turns 14.4; $N=26, W=103 ; Z=-1.34, P=0.18$; Table 1). Also similar to the overall data set, sex did not significantly affect head-turning responses. Females turned an average of 10.1 times in response to non-signature whistles of related animals and 11.0 times to whistles of unrelated animals $(N=13, \quad W=39.5 ; \quad Z=-0.42, \quad P=0.67)$. Males again showed a slightly greater, although still nonsignificant, tendency to turn more toward non-signature whistles of unrelated animals (mean $=17.8$ ) than to related animals $\quad($ mean $=14.2 ; \quad N=13, \quad W=16.5$; $Z=-1.47, P=0.14)$. Finally, presentation order still did not have a significant effect on head-turning responses when possibly compromised experiments were removed (mean head turns toward the first and second stimuli were 14.4 and 12.3; $N=26, W=94.5 ; Z=-1.59, P=0.11$ ).

Acoustic responses to non-signature whistle playbacks were also examined qualitatively. On 14 occasions, the target dolphin copied the playback stimulus (Fig. 3), as assessed by one experienced observer based on contour similarity. Six males were found to produce a similarly shaped non-signature whistle contour, which we called the "M" whistle based on its overall shape (Fig. 4). Although these whistle responses will be subjected to further quantitative analyses in the future, preliminary results suggest that target animals were equally likely to produce copies and " $\mathrm{M}$ " whistles in response to stimuli produced by related and unrelated animals (in fact, seven animals produced copies or " $\mathrm{M}$ " whistles in response to both stimuli), further suggesting that dolphins do not recognize voice cues.

\section{Discussion}

Our results show that dolphins likely do not use voice cues to identify other individuals and instead carry out individual identification by means of the frequency modulation pattern of signature whistles alone. In experiments using protocols identical to the present study, dolphins turned significantly more toward the playback speaker when they heard playbacks of either natural (Sayigh et al. 1999) or synthetic (Janik et al. 2006) signature whistles of close relatives versus known unrelated animals, indicating that they recognized these whistles as identifying a specific individual. This difference was not observed in response to playbacks of non-signature whistles. Given that sound production is affected by water pressure and thus depth (Ridgway et al. 2001; Jensen et al. 2011), it is perhaps not surprising that voice cues would not be a reliable source of identity information in dolphins. But since dolphins live in fluid, fission-fusion societies (Wells et al. 1987; Connor et al. 2000) where vision is of limited usefulness due to poor water clarity and reduced light at depth, the need for reliable signals to identify one another is likely great. Signature whistles have been found to comprise approximately $50 \%$ of all whistles produced by free-ranging 

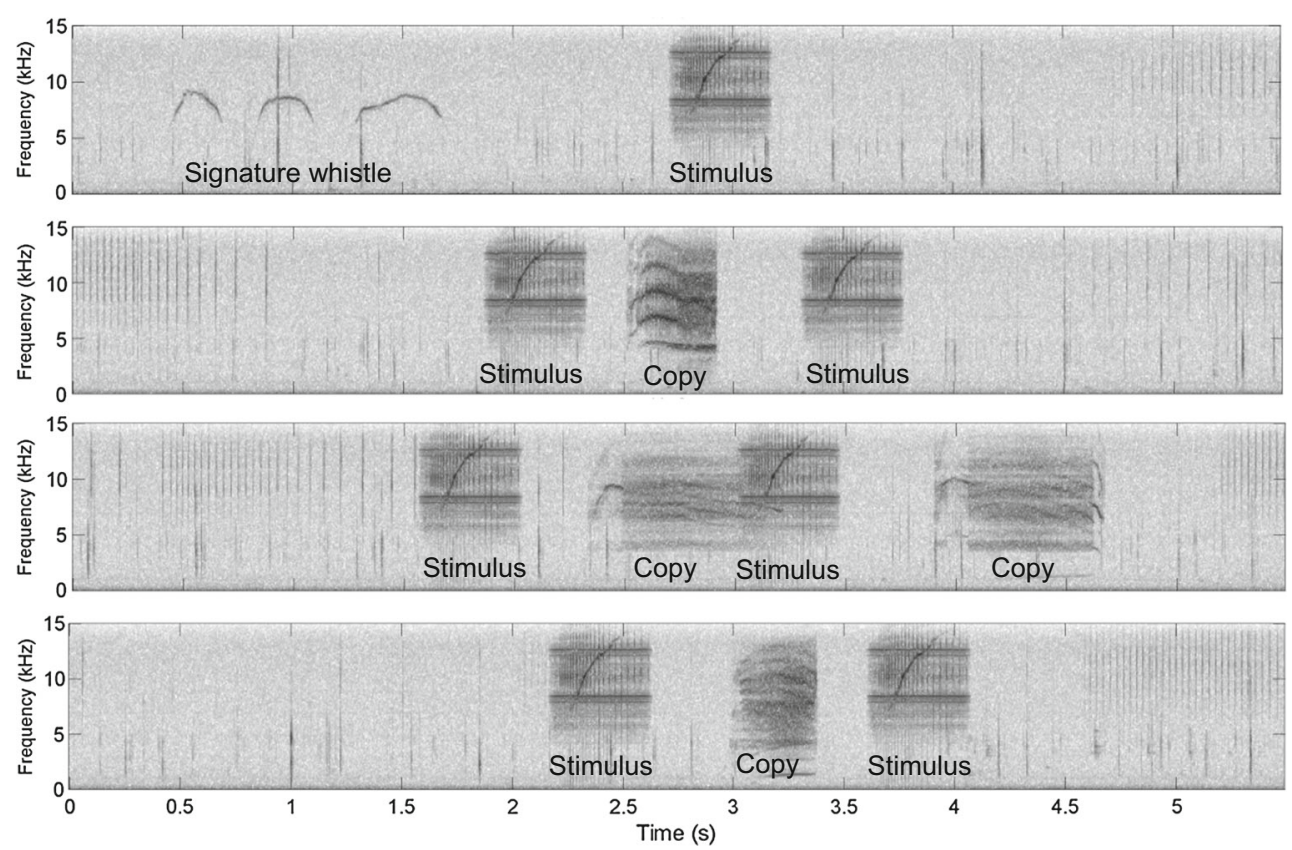

Fig. 3 Spectrogram of copying of a noisy non-signature playback stimulus. A 22 -s sequence is divided into four 5.5 -s sections (top panel 0-5.5; second panel 5.5-11; third panel 11-16.5; bottom panel 16.5-22). The target animal's signature whistle is visible at the

dolphins in Sarasota Bay, Florida (Cook et al. 2004), illustrating their importance in the natural communication system of dolphins.

Our results raise the question of how dolphins perceive copies of signature whistles, if voice cues are not involved in individual recognition. Several studies of whistle imitation have suggested that dolphins may include characteristic features in their copies that may render them recognizable as copies to other animals (e.g., Tyack 1986; King et al. 2013). In fact, the lack of recognizable voice cues may necessitate the use of such features in whistle copies in order for signature whistles to function as individual identifiers.

However, as is always the case with negative results, we cannot rule out alternative explanations for our data. One of the most obvious is the possibility that dolphins use nonsignature whistles differently than signature whistles and thus are not motivated to respond in the same way to the two types of whistles. However, the capture-release situation is associated with increased stress for the animals (Esch et al. 2009b), and we think it is unlikely that animals would ignore the sudden and unexpected appearance of a close relative that could provide support, just because of the whistle type that it produced. Turning responses are reliable indicators of animals trying to explore a stimulus, and thus are what we would have expected in this context when we simulated the arrival of closely related individuals. As mentioned above, our previous studies showed that beginning, followed by a stimulus presentation and then several stimulus-copy exchanges. Frequency (up to $15,000 \mathrm{~Hz}$ ) is on the $y$ axes, and time in seconds is on the $x$ axes. Spectrogram settings included a 1024 point Hanning window with 50\% overlap

in the identical context, dolphins reacted strongly to the perceived presence of such allies when hearing their signature whistle (Sayigh et al. 1999) or even just a synthetic version of their signature whistle (Janik et al. 2006).

Another possible explanation for the observed lack of differential response is that we did not have a sufficient sample size to detect a significant effect. When we reached a sample size comparable to our earlier playback studies (Sayigh et al. 1999; Janik et al. 2006), we found nonsignificant results, but also found greater variability in the data than in our previous studies. We therefore decided to increase our statistical power by increasing the sample size. When sample size increased from 26 to 40 experiments, the results remained nonsignificant, and all trends in mean values of head turns stayed the same, giving us much more confidence in the robustness of the current results. Our current sample size (40) is greater than the combined sample (34) of our two earlier studies.

Dolphins showed a greater, although nonsignificant, tendency to respond to the first stimulus, suggesting a possible "surprise" effect. It is perhaps to be expected that animals might show initial interest to the unexpected appearance of another animal nearby. However, it is notable that in experiments involving signature whistles (Sayigh et al. 1999; Janik et al. 2006), responses were stronger to related animals regardless of presentation order. In other words, the greater salience of a whistle coming from a related individual masked any possible "surprise" 


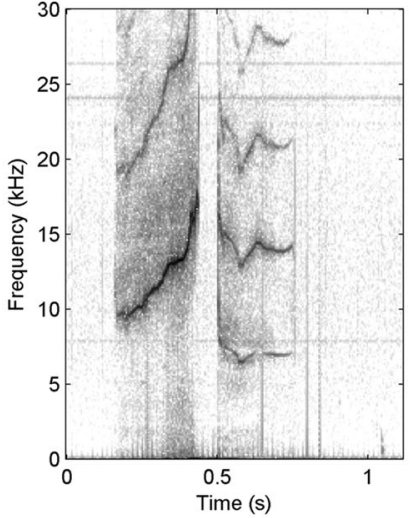

FB92

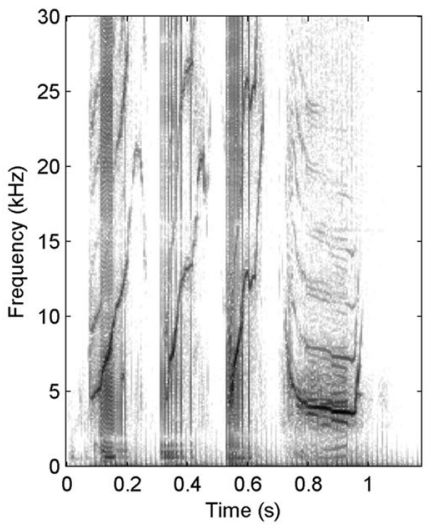

FB196

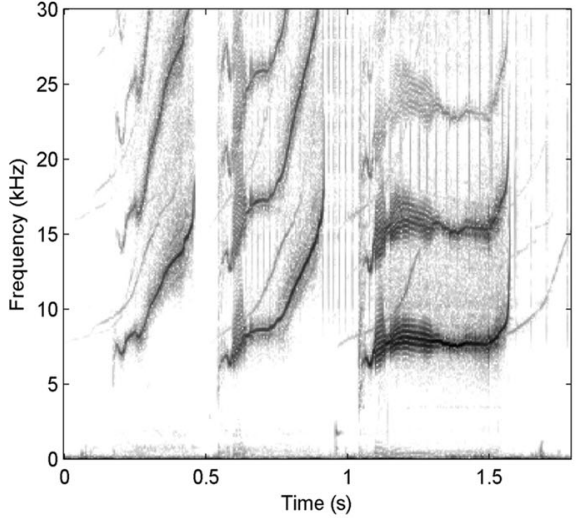

FB178

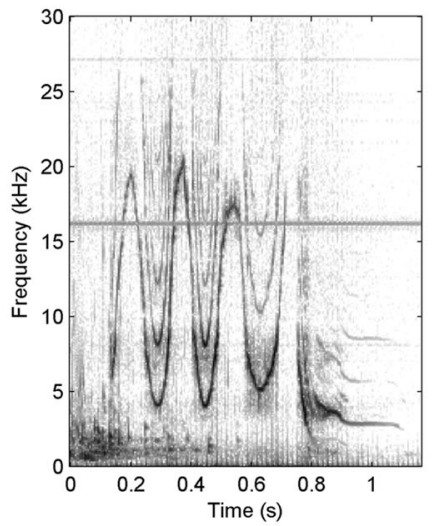

FB188

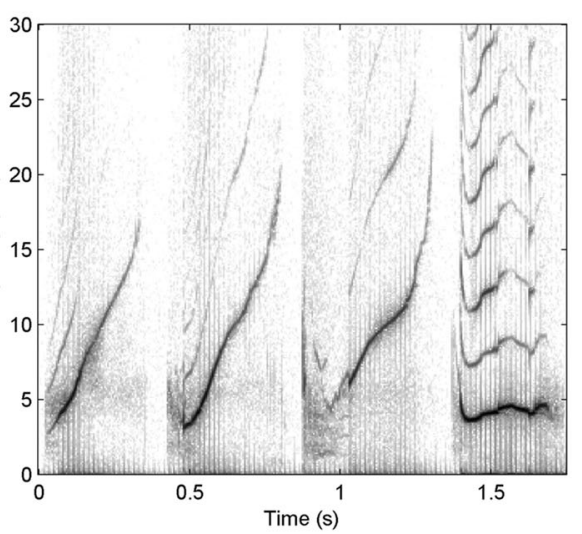

FB196

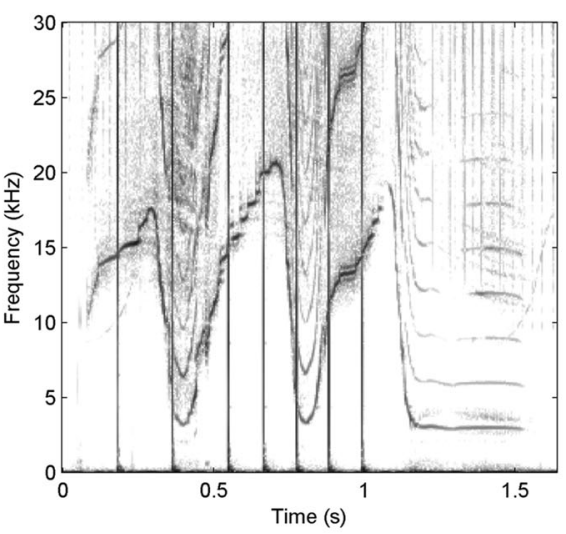

FB178
Fig. 4 Spectrograms of similar non-signature whistle responses (called "M" whistles) to non-signature whistle playbacks by four different males (with two examples from each of two males, FB178

effect. Further, in the present study, the mean coefficient of association between target and related animals used as stimuli was higher than between target and unrelated animals (although nonsignificant). This could have biased results in favor of stronger responses to related animals, yet this result still was not observed.

To exactly replicate the design of our earlier playback studies, we played back non-signature whistles in the same bout structure as we had played back signature whistle stimuli, with exemplars separated by 1 and $4 \mathrm{~s}$ of silence. Janik et al. (2013) found that while signature whistles typically occur in bouts with inter-whistle intervals of $1-10 \mathrm{~s}$, non-signatures were typically separated by less than 1 or more than $10 \mathrm{~s}$. We expect that if dolphins were able to recognize non-signature whistles of close relatives by means of voice cues, we would still see a differential response as we had in our signature whistle playback studies, regardless of bout structure. But the fact that we did not see a differential response, combined with the fact that our playback stimuli were presented with a bout and FB196). Frequency (up to $30,000 \mathrm{~Hz}$ ) is on the $y$ axes, and time in seconds is on the $x$ axes. Spectrogram settings included a 1024 point Hanning window with $50 \%$ overlap

structure typical of signature whistles, suggests that dolphins may have perceived these whistles as unfamiliar signature whistles. We are currently testing this hypothesis by conducting playback experiments with both non-signature and unknown signature whistles with bout structures typical of both signature and non-signature whistles.

The idea that dolphins perceived the playback stimuli as signature whistles of unfamiliar individuals also creates testable hypotheses about the unusual vocal responses to non-signature playbacks that we observed. We are examining whether copying of playback stimuli is more common in response to unfamiliar stimuli, and whether such copying may also have a social function. In addition, we are currently testing the hypothesis that "M" whistles may be produced by males in the presence of an unfamiliar animal, particularly in situations when the males are associating with a reproductively active female, which our preliminary data suggest to be the case.

Our findings suggest that non-signatures play a very different role in the dolphin communication system than do 
signature whistles: they do not convey individual identity, and there is potential that they convey some degree of context-specific information. While dolphins have been found to produce context-specific pulsed sounds (e.g., Connor and Smolker 1996; Janik 2000), there is yet no evidence for context-specific non-signature whistles. Given the impressive vocal learning skills of dolphins (Janik 2014), it is likely that non-signatures are also learned signals. Much remains to be discovered regarding how nonsignature whistles function in the natural communication system of dolphins.

In summary, our results support the idea that dolphins differ from most other non-human mammals in their use of the frequency modulation pattern of individually distinctive signature whistles, rather than voice cues, for individual recognition. If voice cues became unreliable due to water pressure related changes in the shape of structures relevant for the quality of a sound, the need for individual recognition may have been a strong selective force in the evolution of vocal learning in dolphins (Janik 1999, 2009). Vocal production learning allows dolphins to produce novel whistles that are distinct and recognizable in the marine environment, where visibility is low, olfaction is less functional, and background noise is high. Thus, the combination of compromised voice cues and limitations on other sensory channels may have contributed to the relative prevalence of vocal production learning among marine versus (non-human) terrestrial mammals (Janik and Slater 2000).

Acknowledgements Thanks to the Dolphin Biology Research Institute, in particular Michael Scott and Blair Irvine, for establishing the natural laboratory situation where this work is possible, and for their assistance with the fieldwork. We thank the staff of Chicago Zoological Society's Sarasota Dolphin Research Program (SDRP), in particular Katie McHugh, Jason Allen, and Aaron Barleycorn, for their assistance in the field. Thanks also to SDRP personnel for their ongoing collection of photographic identification data that provided coefficients of association for this work. Thanks to Peter Tyack for contributions to the signature whistle catalog used as playback stimuli. Thanks to Mandy Cook, Carter Esch, Kim Fleming, Claire Stuhlmann, and Lynne Williams for help in the field and in analyzing videos.

Funding Fieldwork for this study was funded by Harbor Branch Oceanographic Institution, Grossman Family Foundation, Dolphin Quest, Inc., NOAA Fisheries, Disney, the Office of Naval Research, Morris Animal Foundations Betty White Wildlife Rapid Response Fund, the Batchelor Foundation, and the Joint Industry Program.

\section{Compliance with ethical standards}

Conflict of interest The authors declare that they have no conflicts of interest.

Ethical approval All applicable international, national, and/or institutional guidelines for the care and use of animals were followed, which include carrying out research under National Marine Fisheries
Service Scientific Research Permit Numbers 522-1569, 522-1785, and 15543 issued to RSW. All procedures performed in studies involving animals were in accordance with the ethical standards of the institution or practice at which the studies were conducted, which include Institutional Animal Care and Use Committee (IACUC) approvals from the Woods Hole Oceanographic Institution to LSS and from Mote Marine Laboratory to RSW. This article does not contain any studies with human participants performed by any of the authors.

Data availability Datasets generated and/or analyzed during the current study are not publicly available because they are currently being used for additional studies. Once these studies are completed, they will be made available from the corresponding author on reasonable request.

Open Access This article is distributed under the terms of the Creative Commons Attribution 4.0 International License (http://crea tivecommons.org/licenses/by/4.0/), which permits unrestricted use, distribution, and reproduction in any medium, provided you give appropriate credit to the original author(s) and the source, provide a link to the Creative Commons license, and indicate if changes were made.

\section{References}

Agafonov AV, Panova EM (2012) Individual patterns of tonal (whistling) signals of bottlenose dolphins (Tursiops truncatus) kept in relative isolation. Biol Bull 39:430-440

Au WW, Branstetter B, Moore PW, Finneran JJ (2012) Dolphin biosonar signals measured at extreme off-axis angles: insights to sound propagation in the head. J Acoust Soc Am 132:1199-1206

Balcombe JP (1990) Vocal recognition of pups by mother Mexican free-tailed bats, Tadarida brasiliensis mexicana. Anim Behav 39:960-966

Belin P (2006) Voice processing in human and non-human primates. Philos Trans R Soc B 361:2091-2107

Boughman JW, Moss CF (2003) Social sounds: vocal learning and development of mammal and bird calls. In: Simmons AM, Popper AM, Fay RR (eds) Acoustic communication. Springer, New York, pp 138-224

Bruck JN (2013) Decades-long social memory in bottlenose dolphins. Proc R Soc B 280:20131726

Burdin VI, Reznik AM, Skornyakov VM, Chupakov AG (1975) Communication signals of the Black Sea bottlenose dolphin. Sov Phys Acoust 20:314-318

Cairns SJ, Schwager SJ (1987) A comparison of association indices. Anim Behav 35:1454-1469

Caldwell MC, Caldwell DK (1965) Individualized whistle contours in bottlenose dolphins (Tursiops truncatus). Nature 207:434-435

Caldwell MC, Caldwell DK (1968) Vocalization of naive captive dolphins in small groups. Science 159:1121-1123

Caldwell MC, Caldwell DK (1971) Statistical evidence for individual signature whistles in Pacific whitesided dolphins, Lagenorhynchus obliquidens. Cetology 3:1-9

Caldwell MC, Caldwell DK, Miller JF (1973) Statistical evidence for individual signature whistles in the spotted dolphin, Stenella plagiodon. Cetology 16:1-21

Caldwell MC, Caldwell DK, Tyack PK (1990) Review of the signature-whistle-hypothesis for the Atlantic bottlenose dolphin, Tursiops truncatus. In: Leatherwood S, Reeves RR (eds) The bottlenose dolphin. Academic Press, San Diego, pp 199-234

Charrier I, Mathevon N, Jouventin P (2002) How does a fur seal mother recognize the voice of her pup? An experimental study of Arctocephalus tropicalis. J Exp Biol 205:603-612 
Cohen J (1988) Statistical power analysis for the behavioral sciences. Lawrence Earlbaum Associates, Hillsdale

Connor RC, Smolker RA (1996) 'Pop'goes the dolphin: a vocalization male bottlenose dolphins produce during consortships. Behaviour 133(9):643-662

Connor RC, Wells R, Mann J, Read A (2000) The bottlenose dolphin. In: Mann J, Connor R, Tyack P, Whitehead H (eds) Cetacean societies: field studies of dolphins and whales. University of Chicago Press, Chicago, pp 91-126

Cook MLH, Sayigh L, Blum J, Wells R (2004) Signature whistle production in undisturbed, free-ranging bottlenose dolphins (Tursiops truncatus). Proc R Soc B 271:1043-1049

Cranford TW, Amundin M, Norris KS (1996) Functional morphology and homology in the odontocete nasal complex: implications for sound generation. J Morphol 228:223-285

de Figueiredo LD, Simão SM (2009) Possible occurrence of signature whistles in a population of Sotalia guianensis (Cetacea, Delphinidae) living in Sepetiba Bay, Brazil. J Acoust Soc Am 126:1563-1569

Esch HC, Sayigh L, Wells R (2009a) Quantification of parameters of signature whistles of bottlenose dolphins. Mar Mamm Sci 25:976-986

Esch HC, Sayigh LS, Blum JE, Wells RS (2009b) Whistles as potential indicators of stress in bottlenose dolphins (Tursiops truncatus). J Mamm 90:638-650

Fripp DC, Owen E, Quintana-Rizzo E, Shapiro A, Buckstaff K, Jankowski K, Wells R, Tyack P (2005) Bottlenose dolphin (Tursiops truncatus) calves appear to model their signature whistles on the signature whistles of community members. Anim Cogn 8:17-26

Gridley TG, Cockcroft VG, Hawkins ER, Lemon Blewitt M, Morisaka T, Janik VM (2014) Signature whistles in free-ranging populations of Indo-Pacific bottlenose dolphins, Tursiops aduncus. Mar Mamm Sci 30:512-527

Harley H (2008) Whistle discrimination and categorization by the Atlantic bottlenose dolphin (Tursiops truncatus): a review of the signature whistle framework and a perceptual test. Behav Process 77:243-268

Janik VM (1999) Origins and implications of vocal learning in bottlenose dolphins. In: Box HO, Gibson KR (eds) Mammalian social learning: comparative and ecological perspectives. Cambridge University Press, Cambridge, pp 308-326

Janik VM (2000) Food-related bray calls in wild bottlenose dolphins (Tursiops truncatus). Proc Biol Sci 267(1446):923-927

Janik VM (2009) Acoustic communication in delphinids. Adv Study Behav 40:123-157

Janik VM (2014) Cetacean vocal learning and communication. Curr Opin Neurobiol 28:60-65

Janik VM, Sayigh LS (2013) Communication in bottlenose dolphins: 50 years of signature whistle research. J Comp Physiol A 199:479-489

Janik VM, Slater PJB (1998) Context-specific use suggests that bottlenose dolphin signature whistles are cohesion calls. Anim Behav 56:829-838

Janik VM, Slater PJB (2000) The different roles of social learning in vocal communication. Anim Behav 60:1-11

Janik VM, Dehnhardt G, Todt D (1994) Signature whistle variations in a bottlenosed dolphin, Tursiops truncatus. Behav Ecol Sociobiol 35:243-248

Janik VM, Sayigh LS, Wells RS (2006) Signature whistle shape conveys identity information to bottlenose dolphins. Proc Natl Acad Sci USA 103:8293-8297

Janik VM, King SL, Sayigh LS, Wells RS (2013) Identifying signature whistles from recordings of groups of unrestrained bottlenose dolphins (Tursiops truncatus). Mar Mamm Sci 29:109-122
Jensen FH, Perez JM, Johnson M, Soto NA, Madsen PT (2011) Calling under pressure: short-finned pilot whales make social calls during deep foraging dives. Proc R Soc B Biol Sci 278(1721):3017-3025

Johnson M, Tyack P (2003) A digital acoustic recording tag for measuring the response of wild marine mammals to sound. IEEE J Ocean Eng 28:3-12

King SL, Sayigh LS, Wells RS, Fellner W, Janik VM (2013) Vocal copying of individually distinctive signature whistles in bottlenose dolphins. Proc R Soc B 280:20130053

King SL, Harley HE, Janik VM (2014) The role of signature whistle matching in bottlenose dolphins, Tursiops truncatus. Anim Behav 96:79-86

Lima A, Le Pendu Y (2014) Evidence for signature whistles in Guiana dolphins (Sotalia guianensis) in Ilhéus, northeastern Brazil. J Acoust Soc Am 136(6):3178-3185

Luís AR, Couchinho MN, dos Santos ME (2015) Signature whistles in wild bottlenose dolphins: long-term stability and emission rates. Acta Ethol 19(2):1-10

Madsen PT, Wisniewska D, Beedholm K (2010) Single source sound production and dynamic beam formation in echolocating harbour porpoises (Phocoena phocoena). J Exp Biol 213:3105-3110

Madsen PT, Jensen FH, Carder D, Ridgway S (2012) Dolphin whistles: a functional misnomer revealed by heliox breathing. Biol Lett 8:211-213

Miksis JL, Connor RC, Grund MD, Nowacek DP, Solow AR, Tyack PL (2002) Cardiac responses to acoustic playback experiments in the captive bottlenose dolphin (Tursiops truncatus). J Comp Psychol 115:227-232

Nakahara F, Miyazaki N (2011) Vocal exchanges of signature whistles in bottlenose dolphins (Tursiops truncatus). J Ethol 29:309-320

Pallant J (2007) SPSS survival manual: a step by step guide to data analysis using SPSS for windows. McGraw Hill, Nova Iorque

Papale E, Buffa G, Filiciotto F, Maccarrone V, Mazzola S, Ceraulo M, Giacoma C, Buscaino G (2015) Biphonic calls as signature whistles in a free-ranging bottlenose dolphin. Bioacoustics 24:223-231

Quick NJ, Janik VM (2012) Bottlenose dolphins exchange signature whistles when meeting at sea. Proc R Soc B 279:2539-2545

Quick NJ, Rendell L, Janik VM (2008) A mobile acoustic localization system for the study of free-ranging dolphins during focal follows. Mar Mamm Sci 24:979-989

Rendall D, Rodman P, Emond R (1996) Vocal recognition of individuals and kin in free-ranging rhesus monkeys. Anim Behav 51:1007-1015

Ridgway SH, Carder DA (1988) Nasal pressure and sound production in an echolocating white whale, Delphinapterus leucas. In: Nachtigall PE, Moore PWB (eds) Animal sonar: processes and performance. Plenum Press, New York, pp 53-60

Ridgway SH, Carder DA, Kamolnick T, Smith RR, Schlundt CE, Elsberry WR (2001) Hearing and whistling in the deep sea: depth influences whistle spectra but does not attenuate hearing by white whales (Delphinapterus leucas) (Odontoceti, Cetacea). J Exp Biol 204:3829-3841

Sayigh LS, Tyack PL, Wells RS, Scott MD (1990) Signature whistles of free-ranging bottlenose dolphins, Tursiops truncatus: stability and mother-offspring comparisons. Behav Ecol Sociobiol 26:247-260

Sayigh LS, Tyack PL, Wells RS, Scott MD, Irvine AB (1995) Sex difference in signature whistle production of free-ranging bottlenose dolphins, Tursiops truncatus. Behav Ecol Sociobiol 36:171-177

Sayigh LS, Tyack PL, Wells RS, Solow AR, Scott MD, Irvine AB (1999) Individual recognition in wild bottlenose dolphins: a field test using playback experiments. Anim Behav 57:41-50 
Sayigh LS, Esch HC, Wells RS, Janik VM (2007) Facts about signature whistles of bottlenose dolphins, Tursiops truncatus. Anim Behav 74:1631-1642

Scott MD, Wells RS, Irvine AB (1990) A long-term study of bottlenose dolphins on the west coast of Florida. In: Leatherwood S, Reeves RR (eds) The bottlenose dolphin. Academic Press, San Diego, pp 235-244

Searby A, Jouventin P (2003) Mother-lamb acoustic recognition in sheep: a frequency coding. Proc R Soc B 270:1765-1771

Sidorova IE, Markov VI (1992) Stereotyped signalization of the bottlenose dolphin: role of social factors. In: Thomas JA, Kastelein RA, Supin AY (eds) Marine mammal sensory systems. Plenum Press, New York, pp 563-573

Sidorova IE, Markov VI, Ostrovskaya VM (1990) Signalization of the bottlenose dolphin during the adaptation to different stressors. In: Thomas JA, Kastelein RA (eds) Sensory abilities of cetaceans: laboratory and field evidence. Plenum Press, New York, pp 623-634

Snowdon CT, Cleveland J (1980) Individual recognition of contact calls by pygmy marmosets. Anim Behav 28:717-727

Tyack PL (1986) Whistle repertoires of two bottlenosed dolphins, Tursiops truncatus: mimicry of signature whistles? Behav Ecol Sociobiol 18:251-257

Tyack PL (2000) Dolphins whistle a signature tune. Science 289:1310-1311

van Parijs SM, Corkeron PJ (2001) Evidence for signature whistle production by a Pacific humpback dolphin, Sousa chinensis. Mar Mamm Sci 17:944-949
Watwood SL, Tyack PL, Wells RS (2004) Whistle sharing in paired male bottlenose dolphins, Tursiops truncatus. Behav Ecol Sociobiol 55:531-543

Watwood SL, Owen ECG, Tyack PL, Wells RS (2005) Signature whistle use by temporarily restrained and free-swimming bottlenose dolphins, Tursiops truncatus. Anim Behav 69:1373-1386

Wells RS (2003) Dolphin social complexity: lessons from long-term study and life history. In: de Waal FBM, Tyack PL (eds) Animal social complexity: intelligence, culture, and individualized societies. Harvard University Press, Cambridge, pp 32-56

Wells RS (2014) Social structure and life history of common bottlenose dolphins near Sarasota Bay, Florida: insights from four decades and five generations. In: Yamagiwa J, Karczmarski L (eds) Primates and cetaceans: field research and conservation of complex mammalian societies, primatology monographs. Springer, Tokyo, pp 149-172

Wells RS, Scott MD (1990) Estimating bottlenose dolphin population parameters from individual identification and capture-release techniques. Rep Int Whal Comm Spec Iss 12:407-415

Wells RS, Scott MD, Irvine AB (1987) The social structure of freeranging bottlenose dolphins. In: Genoways $\mathrm{H}$ (ed) Current mammalogy, vol 1. Plenum Press, New York, pp 247-305

Wells RS, Rhinehart HL, Hansen LJ, Sweeney JC, Townsend FI, Stone R, Casper D, Scott MD, Hohn AA, Rowles TK (2004) Bottlenose dolphins as marine ecosystem sentinels: developing a health monitoring system. EcoHealth 1:246-254 